tackle the longevity revolution; in Norway the government's health board is developing a major investment plan in specialist health services for older people.

A second approach would be to identify the resources that are available to optimise long term care. These might include the knowledge base (which is apparently not being properly used ${ }^{2}$, people and their skills, and funding.

Thirdly, in considering the future of long term care, it would be necessary to understand the perspectives of stakeholders: consumers (older people of current and future generations and their families); providers (the long term care industry); purchasers (both social services and the insurance industry); the health service (primary and secondary); the research community; and government.

This audit report tells a tale of perverse incentives, dysfunctional relationships, and inappropriate time horizons. If it is generalisable to the rest of Britain, there is a severe problem with the entry to nursing home care which has long term implications for individuals, organisations, the health of the population, and the national economy. If we continue to adopt what has been described as a "prosthetic" rather than a therapeutic approach to the long term care of older people, ${ }^{10}$ the consequences for future generations may well be devastating. There is a need for national strategic development to stop people going too early to the wrong place. Agreeing a better way forward would be appropriate before the international year of older persons in 1999.

EDWARD DICKINSON

Research unit

Royal College of Physicians,

London NW1 4LE

\footnotetext{
1 Department of Health. Implementing caring for people: assessment special study. London: Department of Health, 1993.

2 Bennet M, Smith E, Millard PH. The right person? The right place? The right time? An audit of the appropriateness of nursing home placements post Community Care Act. London: Department of Geriatric Medicine, St George's Hospital Medical School, 1995.

3 Challis D, Carpenter I, Traske K. Towards a national standard assessment instrument for nursing and residential home care. Canterbury: Personal Social Services Research Unit, 1995.

4 Audit Commission. United they stand. Co-ordinating care for elderly patients with hip fracture. London: HMSO, 1995.

5 Health Committee. First report. Lon
care needs. London: HMSO, 1995.

n: HMSO, 1995.

6 Stuck AE, Siu AL, Wieland GD, Adams J, Rubenstein LZ. Comprehensive geriatric assessment: a meta-analysis of controlled trials. Lancet 1993;342:1032-6. (Systematic review of controlled trials.)

7 Lanhorne P, Williams BO, Gilchrist W, Howie K. Do stroke units save lives? Lancet 1993;342:395-8. (Systematic review of controlled trials.)

8 Counsel and Care. Not such private places. London: Counsel and Care, 1991.

9 The Research Unit of the Royal College of Physicians. The CARE scheme (Continuous assessment review and evaluation (CARE). Clinical audit of long term care of elderly people. London: RCP, 1992.

10 MRC Topic Review. The health of the UK's elderly people. London: Medical Research Council, 1994.
}

\title{
Promoting environmental health
}

\section{Needs closer collaboration between the NHS and local government}

The British government's white paper, Health of the Nation, received a cautious welcome on its publication in $1992 .{ }^{1}$ Its critics believed that its approach to health was limited, that it omitted many important issues such as the effects of environment and poverty, and that it implied ditching the World Health Organisation's comprehensive Health For All strategy. ${ }^{2}$ Since then, WHO has met with the European Union in Helsinki in 1994 and approved a model environmental health action plan, ${ }^{3}$ which Britain has been asked to pilot. ${ }^{4}$ The result gives us a clear view of the British government's segmental approach to Health For All. ${ }^{5}$ It also raises issues about who should do what in promoting environmental health.

Britain's environmental health action plan is a simple list of what the government is doing or planning to do about environmental health. ${ }^{5}$ It is not a new agenda and therefore contains no new policy initiatives. Nor does it feature much about research and development. While some issues (such as air pollution and asthma, or oestrogenic waste and subfertility) are briefly mentioned, the plan does not show how these are prioritised or how funding decisions are to be made. The plan's opacity compares unfavourably with the NHS research and development initiative .

Britain's action plan is only a part of the government's overall strategy for the environment. ${ }^{7}$ It will be supported by a panel of experts on sustainable development, ${ }^{8}$ a national think tank,a cabinet environment committee to consider the environmental impact of policy proposals, and a parallel public education campaign, "Going for Green." All of this is quite separate from the implementation of Health of the Nation. Inevitably, with two separate structures there will be failures of communication. Inevitably, the government's dualistic structure will reinforce the message that Health of the Nation is to be separate from environmental health at field level, which could endanger the NHS's influence in environmental health.

Local government will almost certainly take the lead on environmental health at local level, most probably through the environmental improvement programme, Local Agenda 21, that arose from the Earth Summit in Rio de Janeiro in $1992 .{ }^{9}$
This is sensible, but, unless the NHS's role is written into the action plan, uncooperative local authorities may exclude health authorities from the process. The worst possible outcome would be an NHS programme on Health of the Nation running independently of local authority environmental programmes, with no cross fertilisation. This is happening already in some parts of the country, where local government initiatives have undermined local Healthy City initiatives, ${ }^{10}$ even to the extent of making them non-viable.

So, who should promote health promotion? The action plan is unclear as to whether or not environmental health encompasses individual behaviour. If it does, local authorities will argue that they need their own health specialists, and there will be a split between professionals working on Health of the Nation and those involved in implementing the action plan. The most likely result of this would be health promotion specialists defecting to local government.

There is an additional complication. Implementing Health of the Nation depends on developing alliances to cover settings like "healthy homes." But environmental issues need community development. This process is familiar to people involved in local government and health promotion, but most doctors will have to learn the new techniques of empowerment if they are to play a meaningful part. ${ }^{11}$ If they fail to do this they may lose their influence over environmental health and health promotion and possibly even over large chunks of Health of the Nation. The separation of the Health of the Nation from the environmental health action plan demands that the NHS's role is clearly enunciated with mandatory links to Health of the Nation. Then, with appropriate education of health professionals about community development, the programmes can be implemented side by side.

And what of Health For All? Clearly, the British government does not favour the idea of a unified strategy for action on health and the environment. What is more, Health of the Nation continues to ignore two important goals of Health for All-equity and subsidiarity. There is little we can do about that; but the environmental health action plan provides an 
opportunity for closer collaboration between the NHS and local government, and political action at local level is the basis of implementation. Agreement to deal with issues not taken up by central government may well be reached by local partners who see the need to act out unpopular policies in their own district. If this opportunity is taken, Britain could move much closer to achieving the goals of Health For All.

JOHN DWILLIAMSON

Principal research fellow in public health medicine

Faculty of Health,

University of Brighton,

Brighton BN19PH
1 Department of Health. The health of the nation-a strategy for health in England. London: HMSO, 1992. (Cmnd 1986.)

2 World Health Organisation. Global strategy for health for all by the year 2000. Geneva: WHO, 1981.

3 World Health Organisation. Helsinki declaration on action for environment and health in Europe. Copenhagen: WHO (Europe), 1994.

4 World Health Organisation. Environmental health action plan for Europe. Copenhagen: WHO (Europe), 1994.

5 Department of the Environment, Department of Health. UK environmental action plan: public consultation draft, August 1995. London: DoE/DoH, 1995. (Consultation ended on 27 October 1995.)

6 Department of Health. Research for Health. London: HMSO, 1993.

7 Sustainable development - the UK strategy. London: HMSO, 1994. (Cmnd 2426.)

8 British Government Panel on Sustainable Development. First report, fanuary 1995. London: Department of Environment, 1995.

9 UN Commission on Environment and Development. Agenda 21 New York: UNCED, 1992.

10 Ashton J, ed. Healthy cities. London: Open University Press, 1992.

10 Ashton J, ed. Healthy cities. London: Open University Press, 1992.

World Health Organisation. Health, environment and development: approaches to drafting country level strategies for human well-being under Agenda 21. Geneva: WHO, 1993.

\section{Enteral nutrition after surgery}

\section{Not routinely indicated in well nourished patients}

Perioperative nutritional support, whether by the enteral or parenteral route, remains controversial. Its efficacy in many circumstances is unproved and the indications for using it are unclear. Nutritional support can be expensive and is not without complications. Its use must therefore be shown to improve outcome in terms of improved survival, reduced complication rates, decreased hospital stay, or improved quality of life. While several studies have evaluated the use of perioperative parenteral nutrition, few have examined the perioperative role of enteral feeding.

In this issue of the $B M \mathcal{F}$, Carr et al (p869) report a randomised controlled trial of immediate postoperative enteral feeding in patients undergoing gastrointestinal surgery. ${ }^{1}$ Twenty eight patients who had undergone elective intestinal resection and primary anastamosis were randomised to receive either postoperative feeding via nasojejunal tube or conventional intravenous fluids. The authors found no significant difference between the two groups in terms of clinical outcomes such as length of hospital stay and the number of days to oral intake. In particular, changes in nutritional status before and after surgery were similar in the two groups. However, the enterally fed patients had significantly higher mean intakes of energy and protein, and lower gut permeability. They also had non-significant reductions in weight loss and complications such as nausea, vomiting, and wound infection.

The authors give no information on the patients' preoperative diagnoses, preoperative nutritional status, type of operation, or time to complete recovery (return to work or full functional capacity). Such data would be helpful. Previously published controlled trials have shown little improvement in outcome from enteral feeding, ${ }^{23}$ but these studied patients with normal body composition or mild malnutrition undergoing major elective operations, who may differ from the patients reported here.

Postoperative weight loss (a mean of $1.8 \mathrm{~kg}$ in patients receiving intravenous fluids in this study) is acceptable because short term undernutrition (10-12 days) does not complicate convalescence after major surgery. ${ }^{3}$ This would therefore not be a reason for recommending routine postoperative nutritional support. In general, well nourished elective surgical patients are not considered to need nutritional support, unless postoperative complications prevent oral intake. The incidence of such complications (bowel obstruction, anastomotic disruption, pancreatitis) is low.

Despite the controversy over who might benefit from perioperative nutritional support, there is no doubt that the enteral route is preferable to the parenteral. At least three clinical trials $^{4-6}$ and a meta-analysis ${ }^{7}$ have documented the superiority of immediate postoperative enteral feeding over parenteral nutrition in patients with blunt and penetrating trauma. Enteral feeding was initiated within 24 hours of injury, was well tolerated, and resulted in a significantly lower incidence of postoperative pneumonia, intra-abdominal abscess, and catheter sepsis. The adverse effects of total parenteral nutrition on the gastrointestinal tract include decreased brush border hydrolase activity, ${ }^{8}$ reduced amino acid transporter activity, ${ }^{9}$ increased mucosal permeability, ${ }^{10}$ and a slight decrease in villus height. ${ }^{10}$

Carr et al found that enterally fed patients developed no increase in gut mucosal permeability. However, the clinical significance of this finding is unclear. Further studies are needed to determine whether changes in permeability accurately reflect susceptibility to clinically significant sepsis of gut origin.

Although nutrition support has been shown to be beneficial in selected patients, the routine use of enteral nutrition in well nourished patients undergoing gastrointestinal surgery cannot be recommended.Perioperative nutritional support seems to be of greatest benefit in severely malnourished patients and in patients at high risk. If reliable criteria for identifying at risk patients were established, the role of nutritional intervention could be studied more scientifically.

WILEY W SOUBA

Professor of surgery and nutrition

Harvard Medical School,

Boston, Massachusetts 02115USA

1 Carr C, Ling EKD, Boulos P, Singer M. Randomised trial of safety and efficacy of immediate postoperative enteral feeding in patients undergoing gastrointestinal resection. $B M \mathcal{F}$ 1996;312:869-71.

2 Veterans Affairs Total Parenteral Nutrition Cooperative Study Group: Perioperative total parenteral nutrition in surgical patients. $N$ Engl f Med 1991;325:525-2.

3 Sandstrom R, Drott A, Hyltander A, Arfvidsson B, Schersten T, Wickstron I, et al. The effect of post operative intravenous feeding (TPN) on outcome following major surgery evaluated in a post operative intravenous feeding (T17) on

4 Kudsk KA, Croce MA, Fabian TA, Minard G, Tolley EA, Poret HA, et al. Enteral vs parenteral feeding: effects on septic morbidity following blunt and penetrating trauma. Ann Surg 1992;217:503-3.

5 Moore EE, Jones TN. Benefits of immediate jejunostomy feeding after major abdominal trauma-a prospective, randomised study. $\mathcal{F}$ Trauma 1986;26:874-1.

6 Moore FA, Moore EE, Jones TN, McCroskey BL, Peterson VM. TEN versus TPN following major abdominal trauma-reduced septic morbidity. $\mathcal{F}$ Trauma 1989;29:916-3.

7 Moore FA, Feliciano DV, Andrassy RJ, McArdle AH, Booth FV, Morgenstein-Wagner TV, et al. Early enteral feeding, compared with parenteral, reduces postoperative septic complications. Ann Surg 1992;216:172-3.

8 Guedon C, Schmitz J, Lerebours E,Metayer J, Audran E, Hemet J,et al. Decreased brush border hydrolase activities without gross morphologic changes in human intestinal mucosa after prolonged total parenteral nutrition of adults. Gastroenterology 1986;90:373-8.

9 Inoue Y, Espat NJ, Frohnapple DJ, Epstein H, Copeland EM, Souba WW. The effect of total parenteral nutrition on amino acid and glucose transport by the human small intestine. Ann Surg 1993;217:604-4.

10 Van der Hulst R Van Kreel BK, Von Meyenfeldt MF, Brummer RJ, Arends JW, Deutz NE, et al. Glutamine and the preservation of gut integrity. Lancet 1993;341:1363-5. 